\title{
Numerical Hydroacoustic Analysis of NACA Foils in Marine Applications and Comparison of Their Acoustic Behavior
}

\author{
Parviz Ghadimi, Saman Kermani, and Mohammad A. Feizi Chekab \\ Deptartment of Marine technology, Amirkabir University of Technology, Hafez Avenue, No. 424, P.O. Box 15875-4413, Teheran, Iran \\ Correspondence should be addressed to Parviz Ghadimi; pghadimi@aut.ac.ir
}

Received 26 May 2013; Accepted 26 June 2013

Academic Editors: F. M. Gerner and G. Juncu

Copyright (c) 2013 Parviz Ghadimi et al. This is an open access article distributed under the Creative Commons Attribution License, which permits unrestricted use, distribution, and reproduction in any medium, provided the original work is properly cited.

\begin{abstract}
One of the most important parameters to be considered in the design process of lifting surfaces for marine applications is the acoustic noise emitted by the designed surface. In the present work, the hydroacoustic fields of NACA0012 and NACA0018 hydrofoils are calculated, and the acoustic behavior of these sections is examined and compared at different angles of attack. The Ansys-CFX Navier-Stokes solver is used for hydrodynamic analysis, and a highly accurate multithread program named ACOPY is developed in Python programming language based on the Ffowcs Williams and Hawkings method for acoustic analysis. The developed code has high capability in parallel programming. Results of hydrodynamic and acoustic analyses have been validated against available data. A parametric study is conducted, and the best integration surface for FW-H method is introduced. The acoustic behavior of the sections is calculated in an extensive parametric study for different angles of attack of the hydrofoils. The operational acoustic fields of the foils have been calculated and compared. The results indicate that NACA0012 hydrofoil is a better choice and, more effective, when the acoustic behavior of the hydrofoil is a significant design criterion.
\end{abstract}

\section{Introduction}

The prediction and calculation of the noise generated from airfoils have been an extensive aero-acoustic research topic in the last half century, both experimentally and numerically. The numerous efforts in this area have been mostly motivated by the desire to understand the nature and the origins of airfoil noise and to find effective applicable methods to minimize it.

However, although lifting surfaces are widely used in marine applications and despite the importance of acoustic noise in marine environments, the noise generation of hydrofoils has been barely considered in acoustic publications. The primordial motivation of the present work is to numerically predict and compare the acoustic behavior of two foil sections, that is, NACA0012 and NACA0018, in marine environment.

Generally, there are two principal ways to numerically calculate sound propagation in a fluid: solving the NavierStokes equations and solving the wave equation. Therefore, the literature is bounded by these two categories.
In the first method, the Navier-Stokes equations are solved for the entire domain in which the observer and the source are included. This method is numerically very expensive for large domains, but all nonlinear phenomena are considered and can be captured [1-9]. Shen et al. [7] in 2004 solved the Navier-Stokes equations for a circular cylinder and NACA0015 airfoil in air using the collocated grid finite volume method. These analyses were carried out at a Reynolds number of 200 and a Mach number of 0.2. Also, Marsden et al. [8] used the LES method for calculating the noise radiation of NACA0012 in turbulent flow in 2008. These analyses have been done in air at a Reynolds number of $5 \times$ $10^{5}$ and a Mach number of 0.22. Meanwhile in 2009, Sandberg et al. [9] solved Navier-Stokes equations for simulating the total noise generated by the laminar flow on an airfoil. In the work, a symmetric NACA air foil with different thicknesses and various angles of attack at $\operatorname{Re}=5 \times 10^{4}$ and $M=0.4$ have been investigated.

In the second method, there are several approaches for solving wave equation such as the Lighthill analogy [10], the Ffowcs Williams and Hawkings (FW-H) [11-22], and the Kirchhoff equations [19-24]. 
Lighthill [10] started the computational acoustic in 1952 and derived the acoustic equation from the momentum and continuity equations. He showed that the equations of arbitrary fluid motion can be rewritten by grouping the nonlinear terms into a source term which is the so-called Lighthill stress tensor [22]. Lighthill's theory was further developed by Ffowcs Williams and Hawkings [11] in 1969 and Farassat and Brenter $[14,16]$ in the 1980s. This approach solves inhomogeneous wave equation.

Kirchhoff's theory was presented in 1882. This theory was originally applied to light diffraction and electromagnetic problems. It was Farassat and Myers who presented Kirchhoff's theory for sound propagation in 1988 [23]. In fact, this theory solves the homogeneous wave equation. In 1990, Atassi [24] used the Kirchhoff theory for predicting the noise radiated from Joukowski airfoil in compressible flow. In this research, effects of thickness, angle of attack, and nonuniform flow at several Mach numbers have been investigated, and the results have been compared with direct numerical solutions. The results show that the Kirchhoff theory has low accuracy compared to direct simulation. Also in 2000, Singer et al. [19] analyzed the scattering noise from circular cylinder and trailing edge of airfoil using the FW-H and Kirchhoff methods. In this analysis, firstly, it has been shown that the Kirchhoff theory is not a confident method for circular cylinders. Then, the noise radiated from trailing edge of an airfoil in $3 \mathrm{Mach}$ numbers $(0.2,0.3$, and 0.4$)$ and Strouhal number equal to 0.12 have been investigated using the FW-H method.

The FW-H method allows nonlinearities on the control surface, whereas the Kirchhoff method assumes a solution of the linear wave equation on the surface. If the linear wave equation is not satisfied on the control surface, the results from the Kirchhoff method change dramatically [20].

As indicated earlier, publications in the field of sound radiation from NACA profiles have been mostly conducted for air environment and at low Reynolds numbers. In the present work, the FW-H method is used for investigating the noise generation and propagation for two NACA profiles with different thicknesses and angles of attack in water at a high Reynolds number.

\section{Numerical Solution}

For any hydroacoustic analysis, the pressure distribution around the source should be firstly computed using a hydrodynamic analysis. Then, by using the FW-H method, the calculated acoustic pressure can be estimated at far field. The theories behind the two-step procedure are explained in this part.

2.1. Hydrodynamic Analysis. The most important step for any hydroacoustic analysis is the calculation of the pressure and velocity field around the body. There are various methods for these calculations such as solving potential theory and the Navier-Stokes equations. When the Navier-Stokes equations are solved, all nonlinearities in the viscous fluid are considered and high accuracy can be reached. Therefore, in hydrodynamic investigations, solving the Navier-Stokes equations leads to better results.

To use the Navier-Stokes equations, three equations should be solved: Continuity (1), Momentum (2) and Energy (3):

$$
\begin{gathered}
\frac{\partial u_{j}}{\partial x_{j}}=0, \\
\frac{\partial u_{i}}{\partial t}+u_{j} \frac{\partial u_{i}}{\partial x_{j}}+\frac{1}{\rho} \frac{\partial P}{\partial x_{i}}=v \Delta u_{i}, \\
\frac{\partial E}{\partial t}+u_{j} \frac{\partial E}{\partial x_{j}}=\phi+\frac{1}{\rho} \frac{\partial}{\partial x_{j}}\left(k \frac{\partial T}{\partial x_{j}}\right) .
\end{gathered}
$$

In the previous equations, $\Delta$ is the Laplacian operator, $E$ is the internal energy per unit mass, $v$ is the kinematic viscosity, $k$ is the thermal conductivity coefficient, $T$ is the temperature, and $\phi$ is the rate of dissipation of mechanical energy per unit mass which is defined as

$$
\phi=\nu\left(\frac{\partial u_{i}}{\partial x_{j}}+\frac{\partial u_{i}}{\partial x_{j}}\right)\left(\frac{\partial u_{i}}{\partial x_{j}}+\frac{\partial u_{i}}{\partial x_{j}}\right) .
$$

These equations can be solved by different numerical methods such as finite difference, finite element, and finite volume methods. Among these numerical methods, finite volume is one of the best methods for complex flows and geometries. Therefore, the Ansys-CFX solver is selected for the hydrodynamic calculations of the foils. This solver implements various turbulence models and has the capability of using structured and unstructured grid.

Once the flow field around the foil is calculated using this flow solver, an acoustic method should be implemented to calculate the far field noise based on the hydrodynamic results. The hydroacoustic method used in this work is explained in next section.

2.2. Hydroacoustic Method. The Ffowcs Williams and Hawkings [11] equation is the most general form of the Lighthill acoustic analogy. This equation is derived directly from the equations of conservation of mass and momentum. Following Brentner and Farassat [16], the FW-H equation may be written in differential form as [19]

$$
\begin{aligned}
\nabla^{2} c^{2} \rho^{\prime}(x, t)= & \frac{\partial^{2}}{\partial x_{i} \partial x_{j}}\left[T_{i j} H(f)\right] \\
& -\frac{\partial}{\partial x_{i}}\left[L_{i} \delta(f)\right]+\frac{\partial}{\partial t}\left[\left(\rho_{0} U_{n}\right) \delta(f)\right],
\end{aligned}
$$

where $\square^{2} \equiv\left(1 / c^{2}\right)\left(\partial^{2} / \partial t^{2}\right)-\nabla^{2}$ is the wave operator, $c$ is the speed of sound, $t$ is the observer time, $\rho^{\prime}$ is the disturbance density, $\rho_{0}$ is the secondary density, $f$ is the domain surrounding the foil section (where $f=0$ is the definition of the integration surface), $\delta(f)$ is the Dirac delta 
function, and $H(f)$ is the Heaviside function. Variables $U_{i}$ and $L_{i}$ are defined by the following:

$$
\begin{gathered}
U_{i}=\left(1-\frac{\rho}{\rho_{0}}\right) v_{i}+\frac{\rho u_{i}}{\rho_{0}}, \\
L_{i}=P_{i j} \widehat{n}_{j}+\rho u_{i}\left(u_{n}-v_{n}\right) .
\end{gathered}
$$

Here, $\rho$ is the total density, $\rho u_{i}$ the fluid momentum, $v_{i}$ is the velocity of the integration surface, and $\widehat{n}_{j}$ is the unit normal on the integration surface. Also, $P_{i j}=p^{\prime} \delta_{i j}$, where $p^{\prime}$ is the perturbation pressure and $\delta_{i j}$ is the Kronecker delta. The subscript $n$ indicates the component of velocity in the normal direction. Certainly, the previous equations are simpler in water than in air. In water and at low Mach numbers, $\rho=\rho_{0}$ and $u_{n}=v_{n}$, thus,

$$
\begin{gathered}
U_{i}=u_{i}, \\
L_{i}=P_{i j} \widehat{n}_{j} .
\end{gathered}
$$

The integral solution of the FW-H equation (5) can be written in terms of the acoustic pressure, $p^{\prime}=c^{2} \rho^{\prime}$, as follows:

$$
\begin{aligned}
p^{\prime}(\vec{x}, t) & =p_{T}^{\prime}(\vec{x}, t)+p_{L}^{\prime}(\vec{x}, t)+p_{Q}^{\prime}(\vec{x}, t), \\
4 \pi p_{T}^{\prime}(\vec{x}, t)= & \int_{S}\left[\frac{\rho_{0}\left(\dot{U}_{n}+U_{\dot{n}}\right)}{r\left(1-M_{r}\right)^{2}}\right]_{\mathrm{ret}} d S \\
& +\int_{S}\left[\frac{\rho_{0} u_{n}\left(r \dot{M}_{r}+c\left(M_{r}-M^{2}\right)\right)}{r^{2}\left(1-M_{r}\right)^{3}}\right]_{\mathrm{ret}} d S, \\
4 \pi p_{L}^{\prime}(\vec{x}, t)= & \frac{1}{c} \int_{S}\left[\frac{\dot{L}_{r}}{r\left(1-M_{r}\right)^{2}}\right]_{\mathrm{ret}} d S \\
& +\int_{S}\left[\frac{L_{r}-L_{M}}{r^{2}\left(1-M_{r}\right)^{2}}\right]_{\mathrm{ret}} d S \\
& +\frac{1}{c} \int_{S}\left[\frac{L_{r}\left(r \dot{M}_{r}+c\left(M_{r}+M^{2}\right)\right)}{r^{2}\left(1-M_{r}\right)^{3}}\right]_{\mathrm{ret}} d S .
\end{aligned}
$$

The dot sign indicates time derivative and $L_{M}=L_{i} M_{i}$, where $M_{i}$ is the vector of Mach number. Also, $r$ is the distance from the source point to the observer. $p_{Q}^{\prime}(x, t)$ is the quadrupole term which is neglected in this research because of its insignificance at low Mach numbers, but methods of calculation for this term are available in reference [15].

The previous integrations are solved numerically on a surface around the solid body named integration surface. The choice of the integration surface affects highly the acoustic results. That is why an investigation is needed to find the best integration surface for each body.

In this research, the FW-H method has been implemented using the multithreading capabilities of Python programming language. The prepared program, named ACOPY (ACO for Acoustics and PY for Python) calculates the acoustic pressure and sound pressure level accurately and quickly by parallel processing.

There is a high volume of data in hydroacoustic problems, and using a single processor leads to long and frustrating calculations. Therefore, ACOPY has been written in Python which has high capability in parallel programming. Generally, the hardware, the algorithm, and the code should be fitted for parallelization.

Parallel algorithms are categorized as four types: single instruction multiple data (SIMD), single instruction single data (SISD), multiple instruction single data (MISD), and multiple instruction multiple data (MIMD). The developed code ACOPY uses SIMD algorithm which is fully stable.

There are various modules in Python for parallel processing. PP is one of the best modules which can be run on Windows and Linux. Also, PP module can be run on symmetric multiprocessing computers (SMP) and cluster systems. Meanwhile, converting a code from serial to parallel processing in Python does not need fundamental changes in the code.

To accomplish the computational tasks outlined in Sections 2.1 and 2.2 for the current problem, the setup of the calculations is explained in the next section.

\section{Problem Setup}

In this part, the hydroacoustic analysis of two hydrofoils is carried out by the FW-H method at high Reynolds number and low Mach number for seven different angles of attack. For solving the FW-H equations, the pressures and velocities on an integration surface should be obtained by solving the Navier-Stokes equations. Therefore, the analysis is divided into two main steps.

3.1. Problem Setup: Hydrodynamics. In the first step, the hydrodynamics of the hydrofoils are analyzed using the powerful Navier-Stokes solver in Ansys-CFX. NACA symmetric profile (9) is used for modeling the hydrofoils:

$$
\begin{aligned}
y=\frac{t}{0.2} c & \\
\times & {\left[0.2969 \sqrt{\frac{x}{c}}-0.126\left(\frac{x}{c}\right)-0.3516\left(\frac{x}{c}\right)^{2}\right.} \\
& \left.+0.2843\left(\frac{x}{c}\right)^{3}-0.1015\left(\frac{x}{c}\right)^{4}\right],
\end{aligned}
$$

where $t$ is the thickness, $c$ is the chord length, and $(x, y)$ is the Cartesian coordinates. In this research, NACA0012 and NACA0018 (shown in Figures 1 and 2) with $c=0.1 \mathrm{~m}$ have been used.

All the characteristics of the domain and the boundary conditions are shown in Figure 3. The upper and lower bounds of the domain are set as free slip wall, while the right and left parts of the domain are set as a symmetry condition. For the inlet boundary, normal speed has been used.

The Reynolds number considered for these hydrofoils is $5 \times 10^{6}$, while $v=1.004 \times 10^{-6}$ in water. Also, the Mach number is 0.0334 . 


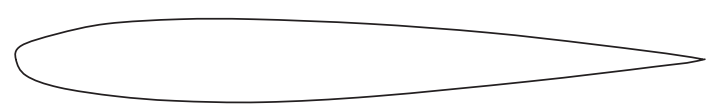

FIgURE 1: Schematic of a NACA0012 section.

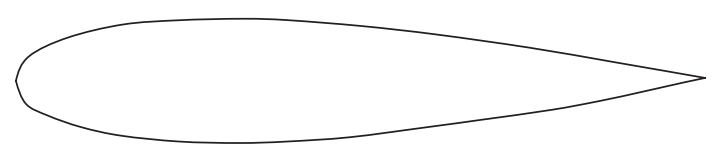

FIgURE 2: Schematic of a NACA0018 section.

The setup of the hydrodynamic analysis is illustrated in Table 1 .

3.2. Problem Setup: Hydroacoustics. After obtaining the pressure distribution around the hydrofoil, the FW-H equations should be solved.

Since the choice of the integration surface may affect the acoustic solutions, in order to have a good estimation of the sound pressure level (SPL) in the far field, the best integration surface around the hydrofoils must be selected. Therefore, five surfaces with different distances from the hydrofoil are analyzed, and by comparing the results with the pressure estimation from the hydrodynamic analysis, one is chosen to be used in all hydroacoustic analyses. Table 2 shows these five cases, and Figure 4 illustrates the five integration surfaces. In Table $2, Z$ is the distance from the hydrofoil, and $C$ is the chord length.

Besides the calculation of the noise itself, it is always important to identify the direction of the noise propagation. Therefore, after the selection of the best integration surface, the acoustic pressure is calculated for both hydrofoils at seven angles of attack for an array of observers placed on a circle with a radius of $80 \mathrm{C}$, in order to better identify the directivity of the hydrofoil noise. Summary of these analyses is presented in Table 3.

Also, it is important to predict the noise propagation behavior as the observer gets far from the source. Thus, the SPL of the noise is calculated for observers placed in 8 directions at distances 50 meters to 2500 meters from the hydrofoil. Summary of these analyses is listed in Table 4, and a schematic view of the directions is demonstrated in Figure 5.

In this research, a total of 14 hydrodynamic analyses and 12440 hydroacoustic analyses have been carried out, and the results are shown and discussed in the next section.

\section{Results and Discussion}

In this section, the results of the mentioned analyses in Tables 3 and 4 are presented in two parts: hydrodynamics and hydroacoustics. Firstly, to ensure the accuracy of the analysis, the hydrodynamic analysis should be validated.

4.1. Results: Validation of Hydrodynamic Analysis. The hydrodynamic analyses of hydrofoils have been conducted for angles of attack from 0 degree to 12 degrees with a step of 2 degrees. In order to validate the hydrodynamic analysis,

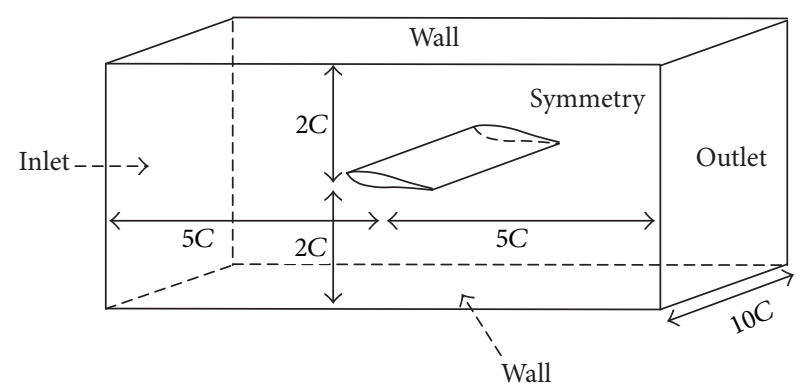

FIGURE 3: Characteristics of the domain and boundary conditions ( $C$ is the chord length).

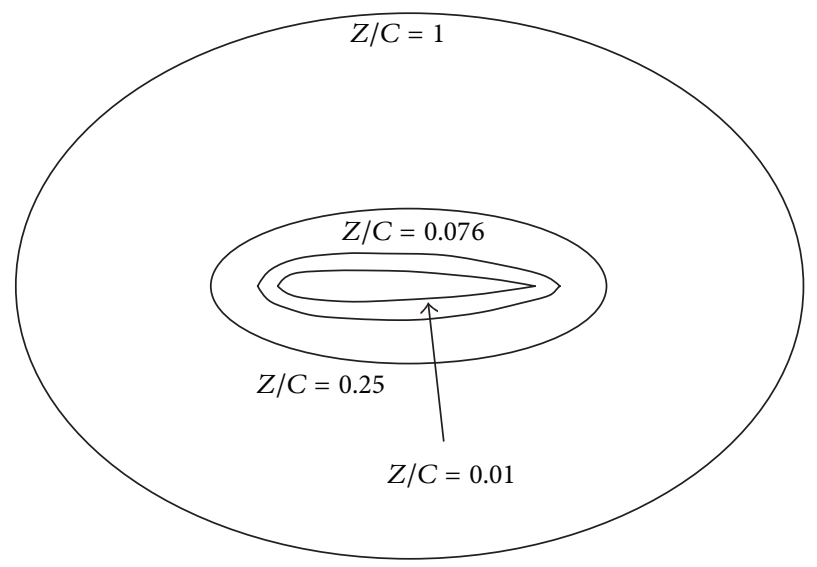

FIgURE 4: Illustration of different integration surfaces around the hydrofoil.

the obtained lift coefficients are compared with the available experimental data [25]. Figures 6 and 7 display the comparison of lift coefficients of NACA0012 and NACA0018 hydrofoils with the experimental data.

As evidenced in Figures 6 and 7, the numerical results are in high accordance with the experimental data. The mean deviation from the experimental data is approximately $3.6 \%$ for NACA0018 and $0.95 \%$ for NACA0012 which are very reasonable.

4.2. Results: Hydroacoustic Analysis. In this section, as mentioned before, an effective integration surface is chosen among the surfaces illustrated in Figure 4, and the results of the FW-H code are validated using a comparison between the FW-H and the direct solution by Navier-Stokes equations. Subsequently, the selected integration surface is used to calculate the acoustic noise in the far field at different angles of attack and distances.

4.2.1. Acoustic Validation and Selection of the Best Integration Surface. To find the best integration surface, the analysis has been done for 5 different surfaces and compared with the direct solutions obtained by the Navier-Stokes equations. The sound pressure levels have been measured for 360 observers placed on a circle with $R=0.18 \mathrm{~m}$ from the hydrofoil, while 


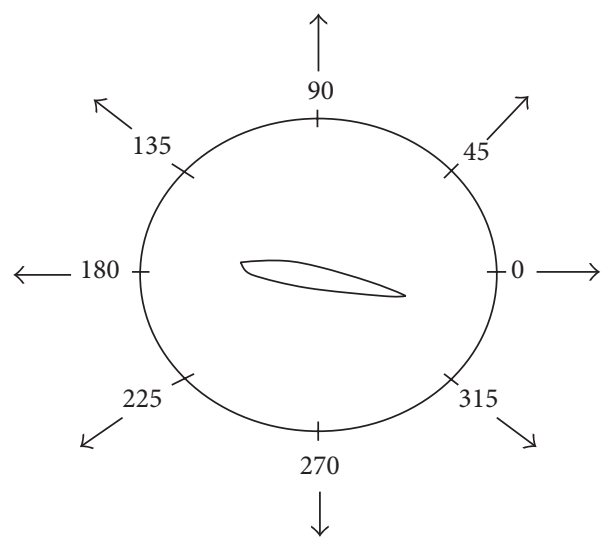

FIgURE 5: Different directions chosen for the far field investigation.

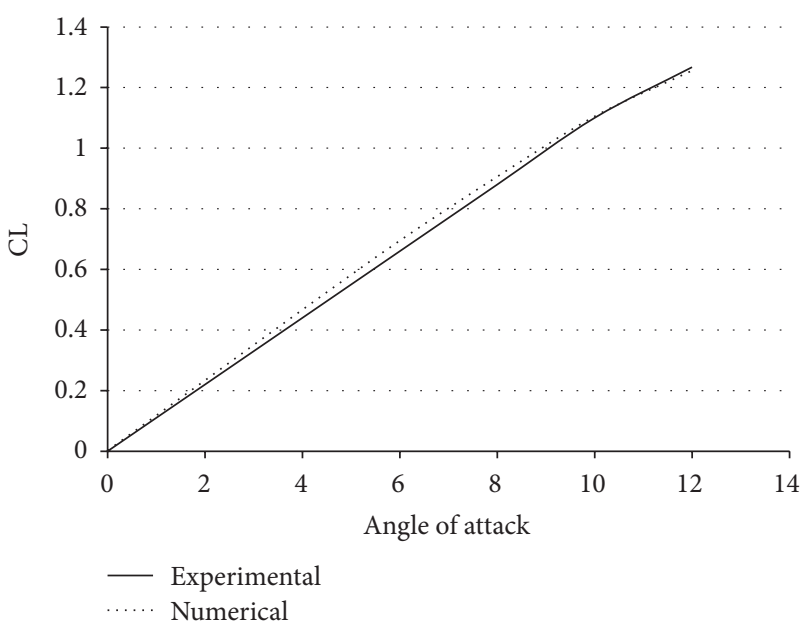

FIgURE 6: Comparison of lift coefficients of NACA0012 with the experimental data.

TABLE 1: List of hydrodynamic analyses.

\begin{tabular}{lccc}
\hline NACA & $\begin{array}{c}\text { Range of angle of } \\
\text { attack }\end{array}$ & Step & $\begin{array}{c}\text { Number of } \\
\text { analyses }\end{array}$ \\
\hline 0012 & $0-12$ degree & 2 degree & 7 \\
0018 & $0-12$ degree & 2 degree & 7 \\
\hline
\end{tabular}

TABLE 2: List of analyses needed for selecting the best integration surface.

\begin{tabular}{lcc}
\hline NACA & $Z / C$ & Number of observer and analysis \\
\hline 0012 & 0 & 360 \\
0012 & 0.01 & 360 \\
0012 & 0.076 & 360 \\
0012 & 0.25 & 360 \\
0012 & 1.0 & 360 \\
\hline
\end{tabular}

the angle of attack of NACA0012 is 10 degrees. The results are plotted in Figure 8.

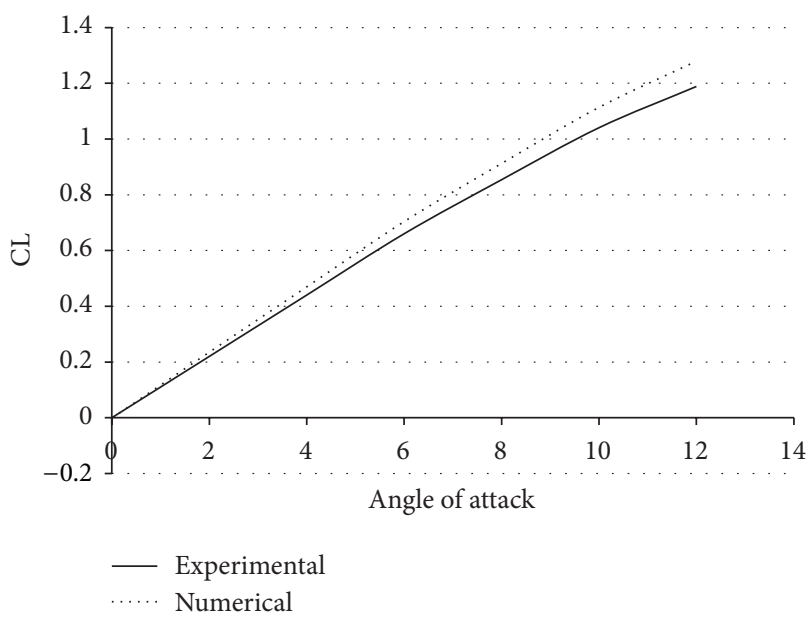

FIGURE 7: Comparison of lift coefficients of NACA0018 with the experimental data.

TABLE 3: List of SPL analyses for two hydrofoils at 7 angles of attack.

\begin{tabular}{lcc}
\hline Foil section & Angles of attack & $\begin{array}{c}\text { Number of } \\
\text { observers on } \\
\text { the circle }\end{array}$ \\
\hline 0012 & $0-12$ with (2 degree step) & 360 \\
0018 & $0-12$ with (2 degree step) & 360 \\
\hline
\end{tabular}

TABLE 4: List of 8 directions analyses.

\begin{tabular}{lcc}
\hline Section & Range of angles of attack & Distance from the observers \\
\hline 0012 & $0-12$ (step $=2$ degrees $)$ & $50 \mathrm{~m}-2500 \mathrm{~m}$ (50 observers) \\
0018 & $0-12$ (step $=2$ degrees $)$ & $50 \mathrm{~m}-2500 \mathrm{~m}$ (50 observers)
\end{tabular}

The sound pressure level is determined by (10), while the reference pressure for water is assumed to be $10^{-6}$ pa:

$$
\mathrm{SPL}=20 \log _{10}\left(\frac{p}{p_{\text {ref }}}\right)
$$




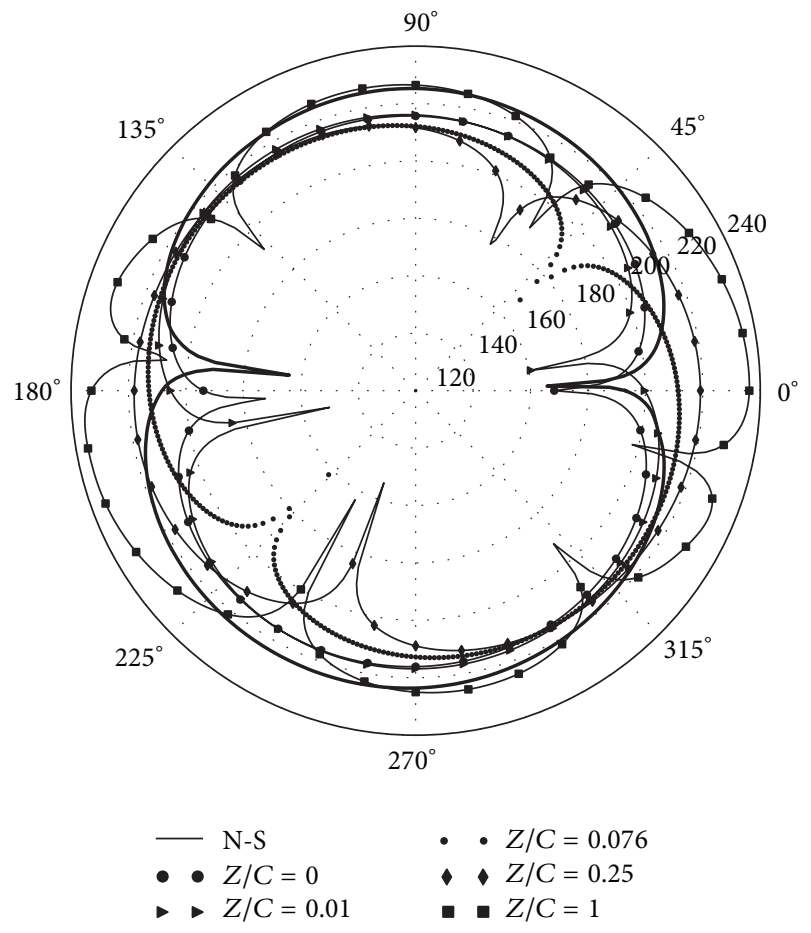

FIgURE 8: Comparison of different integration surfaces.

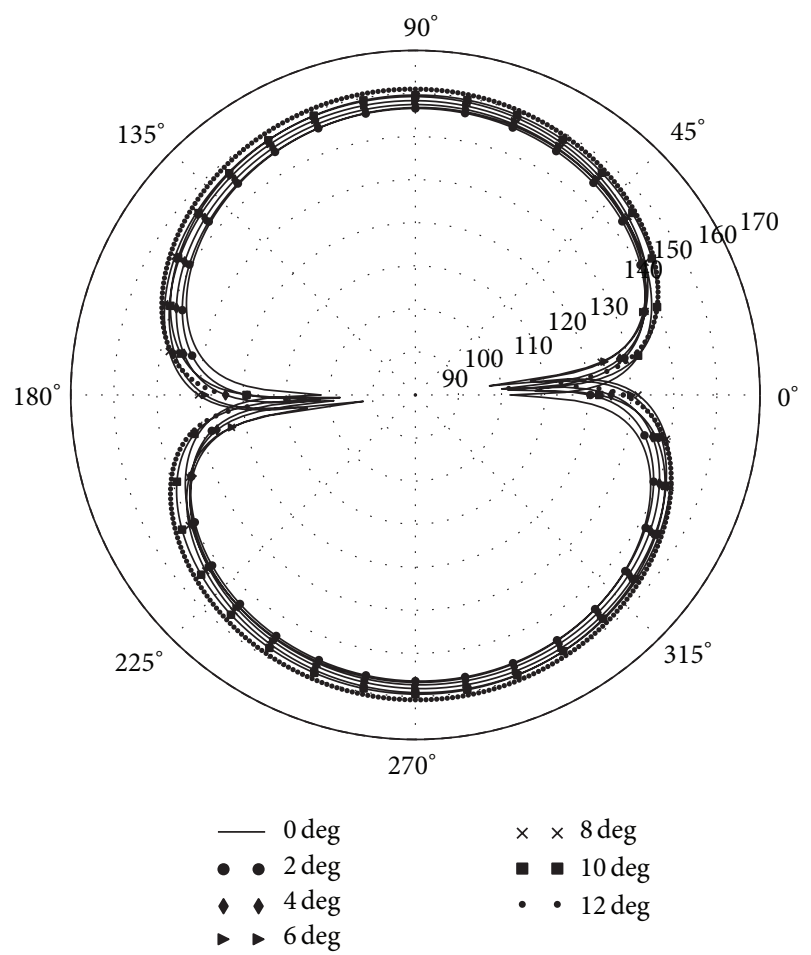

FIGURE 9: Computed SPL of NACA0012 at different angles of attack; 360 observers are placed on a circle with $r=80 \mathrm{C}$.

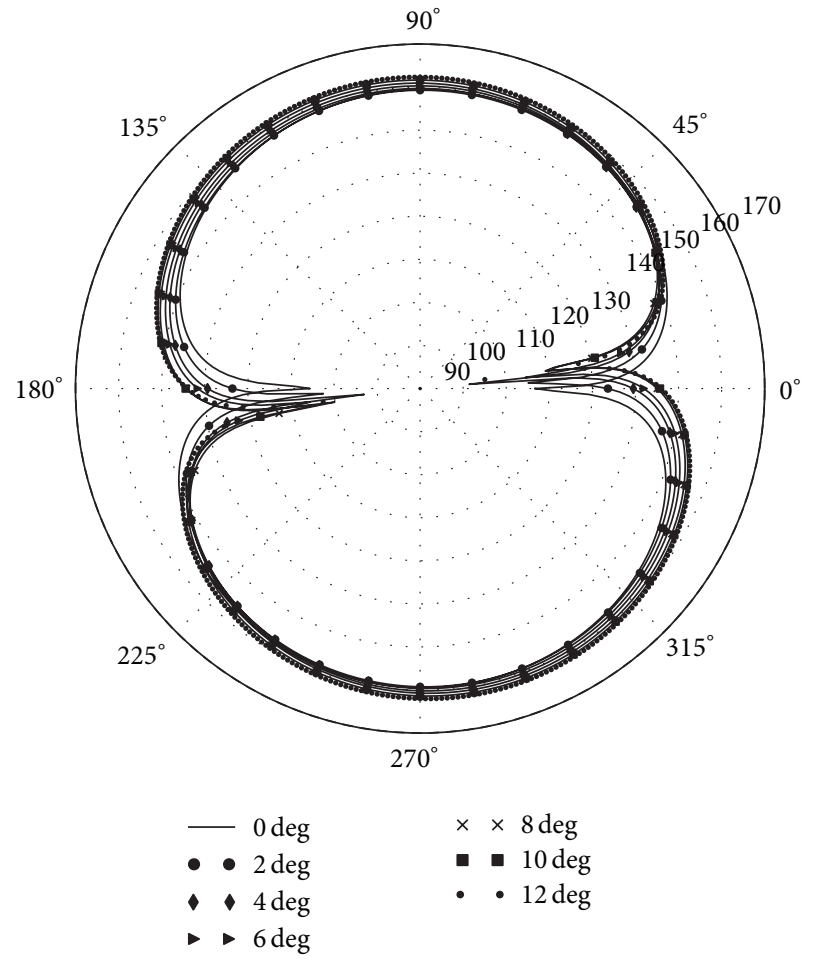

Figure 10: Computed SPL of NACA0018 for different angles of attack; 360 observers are placed on a circle with $r=80 \mathrm{C}$.

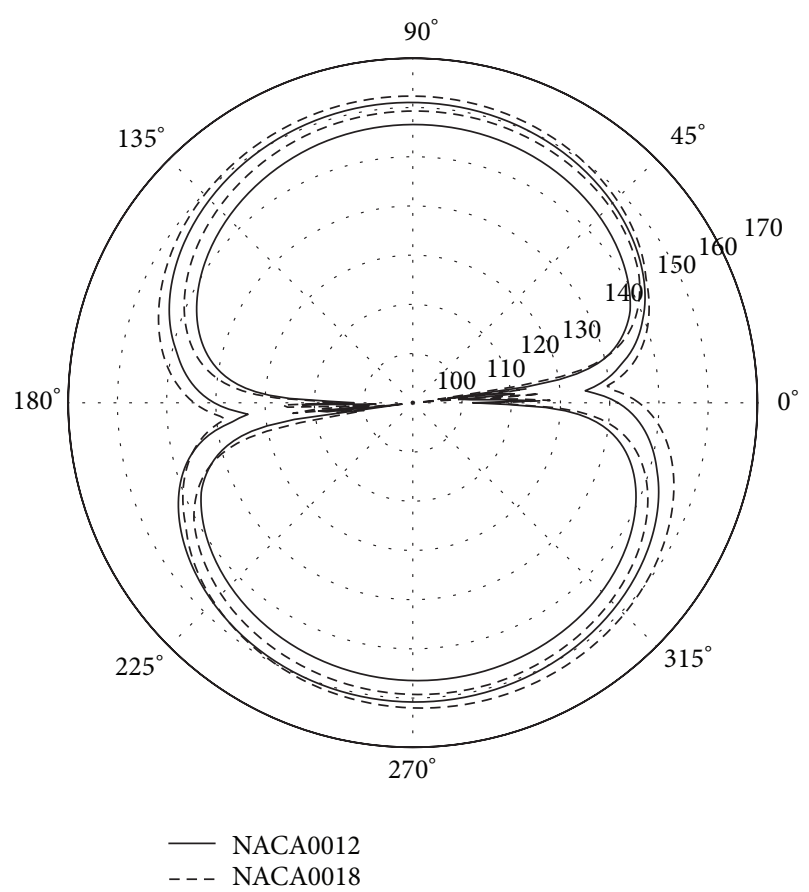

FIGURE 11: The minimum and maximum envelope curves of the noise directivity of NACA0012 and NACA0018. 


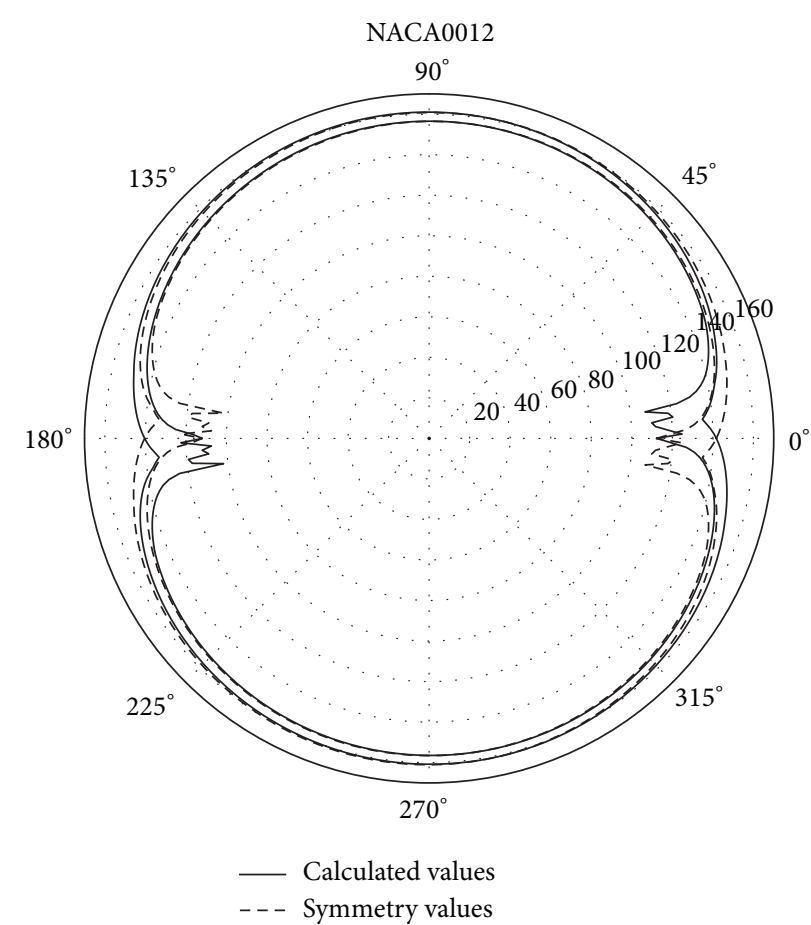

(a)

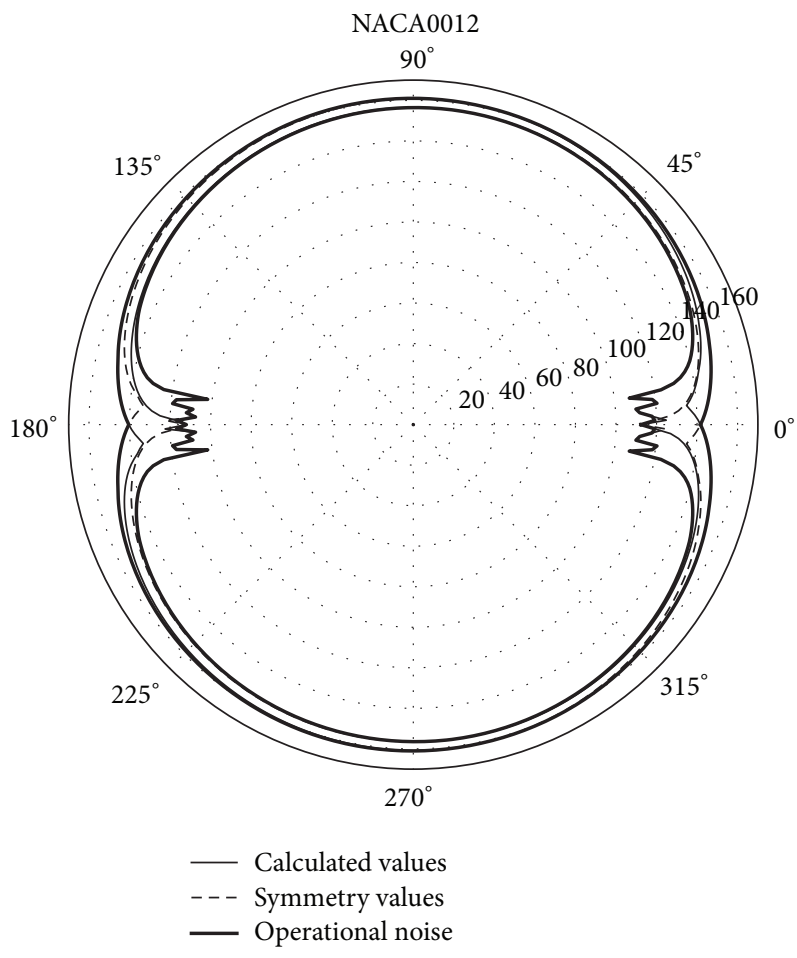

(c)

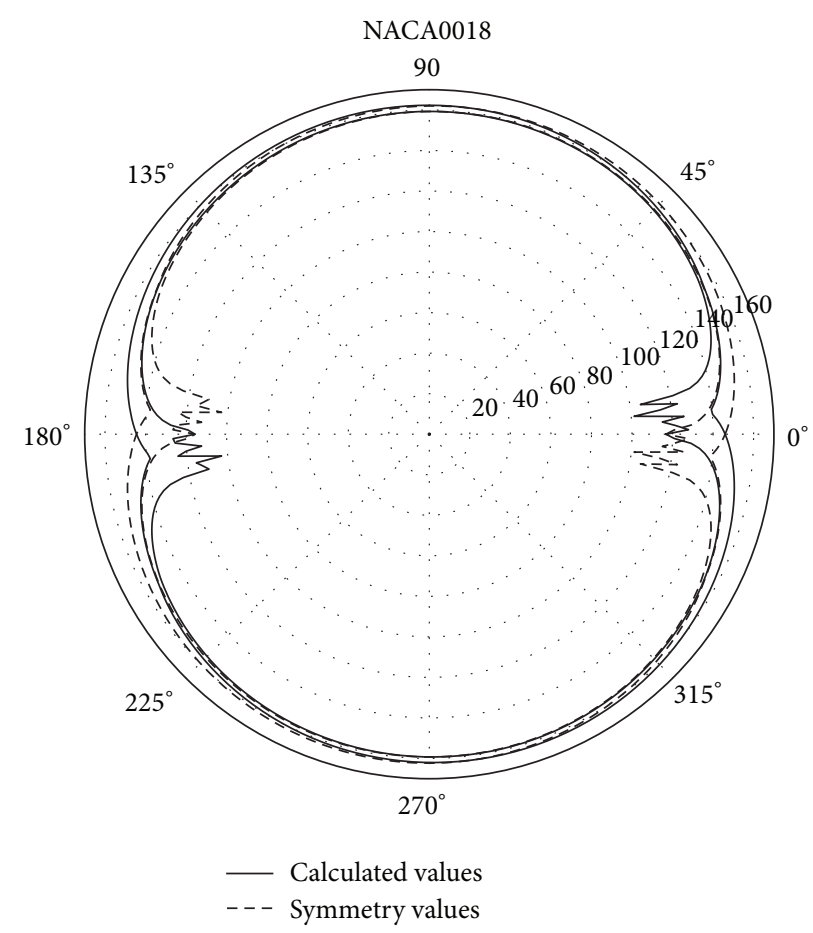

(b)

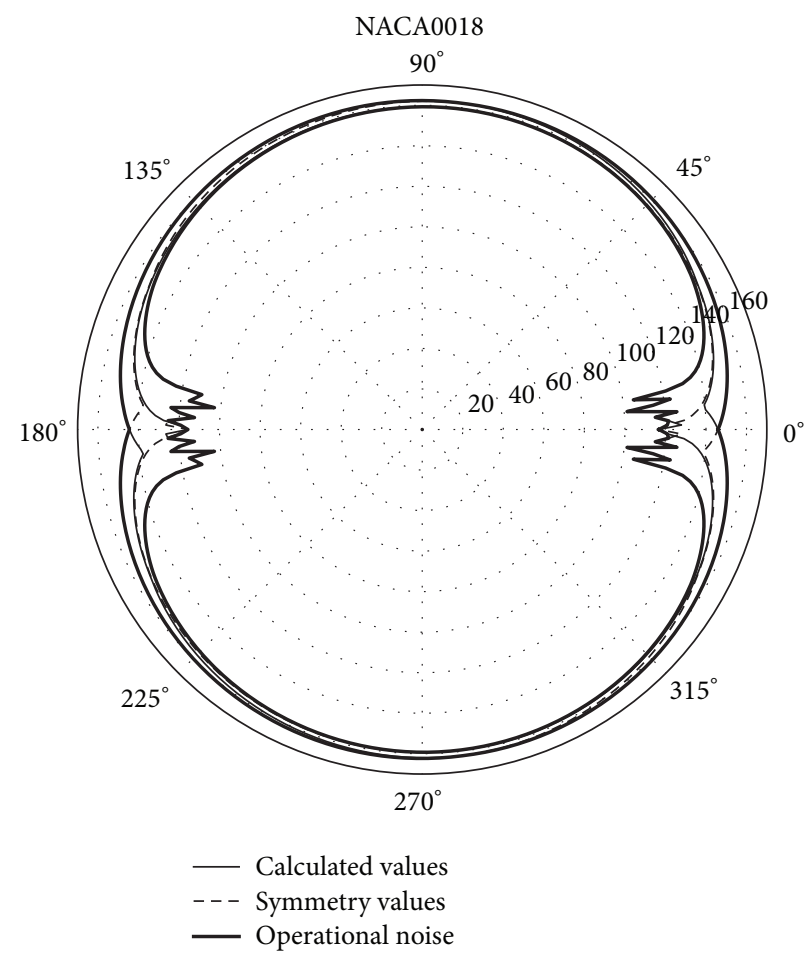

(d)

FIGURE 12: Procedure for obtaining the full operational noise of the hydrofoils.

In Figure 8, $Z$ is the distance of the integration surface to the hydrofoil, and $C$ is the hydrofoil chord length. The polar graph shows that when the hydrodynamic results are steady, the best distance of the integration surface from the hydrofoil is zero, that is, the best integration surface is the surface of the foil itself. The root mean square of the errors in this distance compared with the Navier-Stokes solution is $4.3 \%$. Getting far from the hydrofoil would bring about an increase in the error and would lead to a wrong behavior of the sound pressure level. The cause of this phenomenon can be 


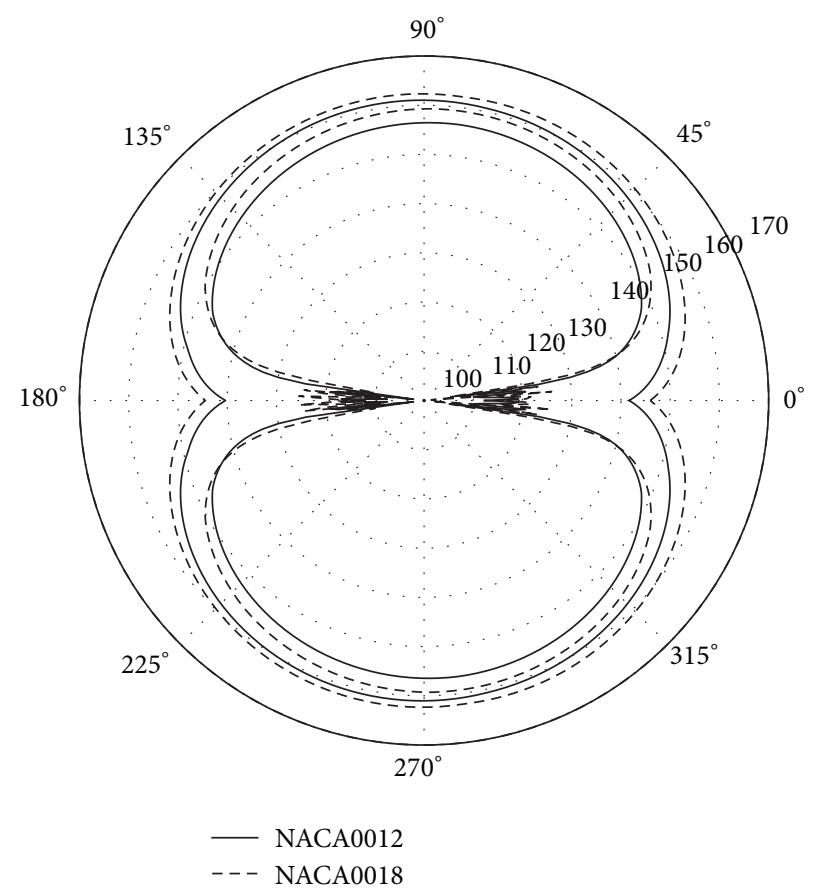

FIGURE 13: Operational noise regions for both sections.

attributed to the shape of the integration surface. When the surface is matched on the hydrofoil, the far field acoustic prediction has more accuracy. At this point, the best integration surface is recognized, and the main analyses can be done with more confidence.

4.2.2. Effects of Angle of Attack on Noise Quantity and Directivity. Computed SPL related to NACA0012 and NACA0018 hydrofoils for seven angles of attack is plotted and compared in Figures 9 and 10. It is observed that the radiated noise is generally increased nonuniformly by increasing the angle of attack in all directions. As observed in Figure 9, the minimum increase range is approximately $4 \mathrm{~dB}$ for NACA0012 and commonly occurs in the area of 90 and 270 degrees. The minimum increase of SPL for NACA0018 is approximately $1 \mathrm{~dB}$ and occurs for the observers placed in the vicinity of 45 and 225 degrees. Meanwhile, the maximum increase in SPL is observed in the vicinity of 0 and 180 degrees for both cases. The overall SPL increase is ranged between $4 \mathrm{~dB}$ (at 90 and $270 \mathrm{deg}$ ) and approximately $25 \mathrm{~dB}$ (at 0 to $180 \mathrm{deg}$ ) for NACA0012 and between $1 \mathrm{~dB}$ (at 45 and $225 \mathrm{deg}$ ) and approximately $30 \mathrm{~dB}$ (at 0 to $180 \mathrm{deg}$ ) for NACA0018.

On the other hand, the rotation of hydrofoil causes a counter-rotation of the directivity, relative to the angle of attack. In fact, the dramatic increase of SPL at 0 and 180 degrees is mostly caused by this rotation and the slight change of direction of the minimum SPL. It can be deduced that the real SPL increase at 0 and $180 \mathrm{deg}$ is in the range of $\sim 10 \mathrm{~dB}$ for NACA0012 and $\sim 6 \mathrm{~dB}$ for NACA0018.

These observations lead to the fact that NACA0012 is more sensitive to the change of angle of attack. Also, the effect of angle of attack on the noise generation of the hydrofoil is mostly observed at the leading edge and trailing edge of the foil.

It is important to remember that generally, the angle of attack of a hydrofoil in operation is not constant and varies intentionally when it is used as an active lifting surface or unintentionally when it is operated as a passive part. Therefore, when deciding about the section of the hydrofoil, from the acoustic view, the noise generation of the hydrofoil should be considered in the operation range.

To define the operational noise of the hydrofoil, the operational maximum noise should be extracted from the directivity charts, by obtaining the envelope curve of all the noise data for each section. Also, the minimum operational noise can be extracted in the same way by plotting the envelope curve on the minimum of all noise data. By doing so, the operational noise of the hydrofoil can be defined as the region between the two curves. By implementing this procedure on both sections, the directivity chart of the operational noise of NACA0012 and NACA0018 hydrofoils is obtained and plotted in Figure 11.

However, a hydrofoil's angle of attack is not generally limited to one side and can be rotated in the reverse direction (i.e., from 0 to -12 deg.); in which case, the noise directivity would be a mirror of Figure 11 relative to the 0 degree axis. To obtain the real operational noise of the hydrofoil, all states of the hydrofoil should be considered. The procedure for extraction of the complete operational noise of the hydrofoils is illustrated in Figure 12.

As shown in Figure 12, the new envelope curves define the operational noise region of the hydrofoils. By plotting the operational noise regions of both sections in one chart 


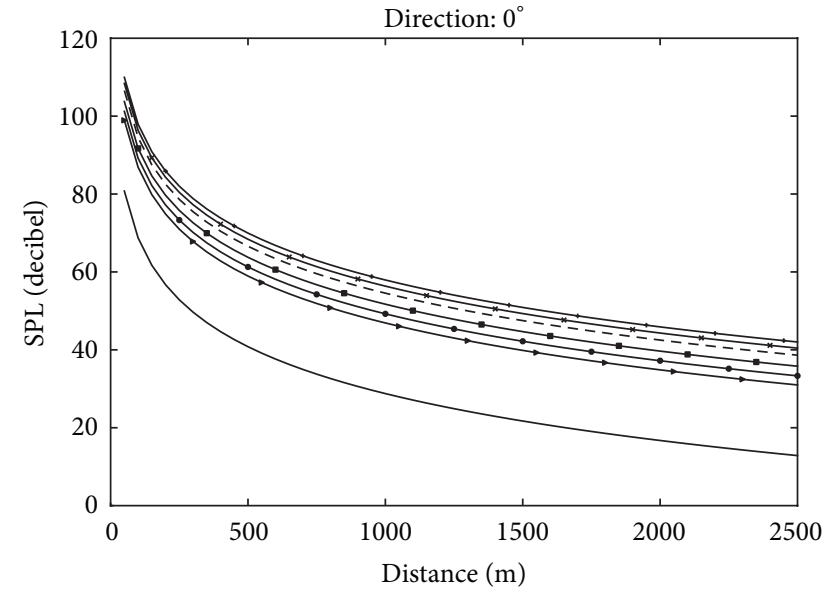

(a)

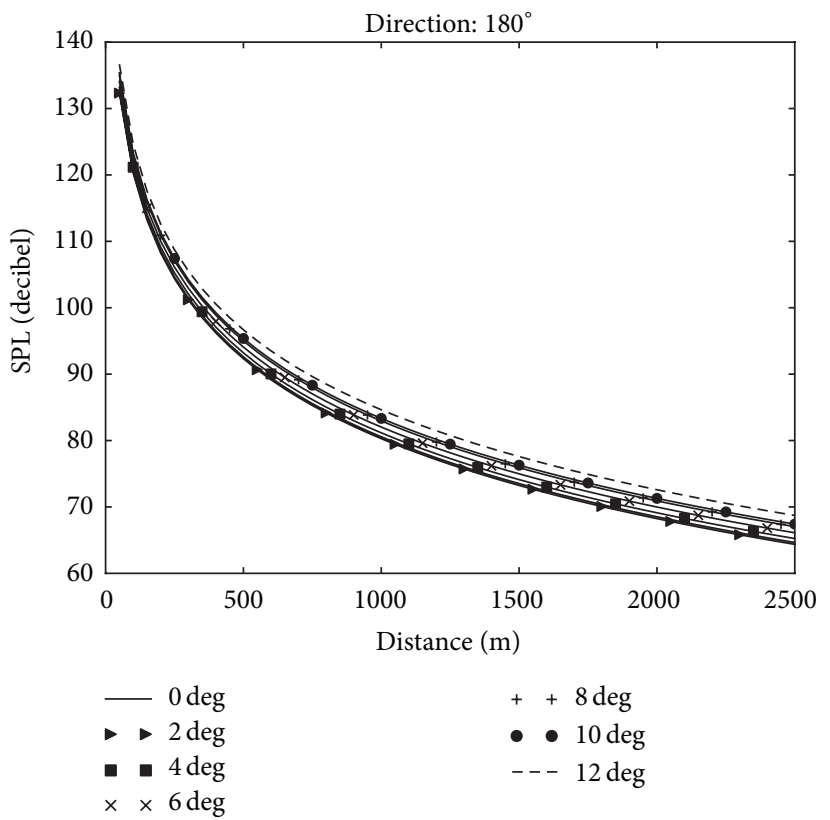

(c)

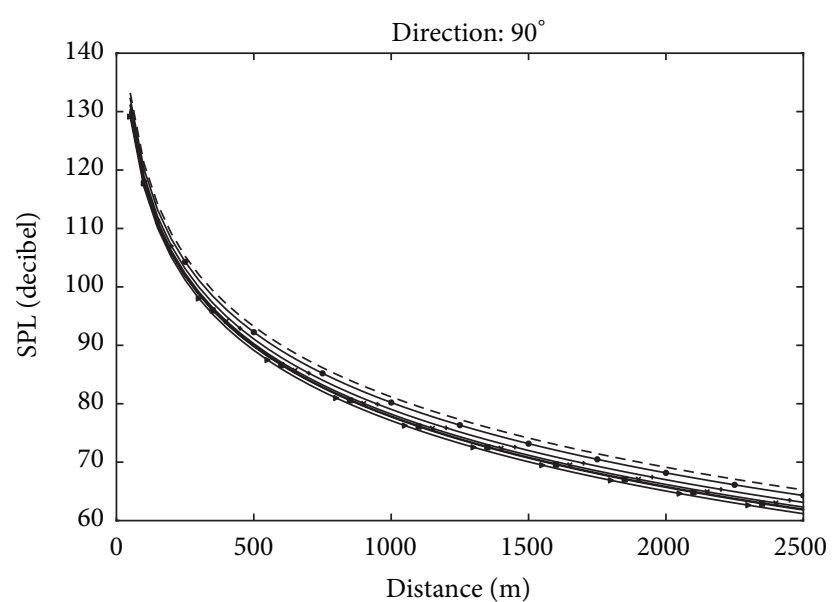

(b)

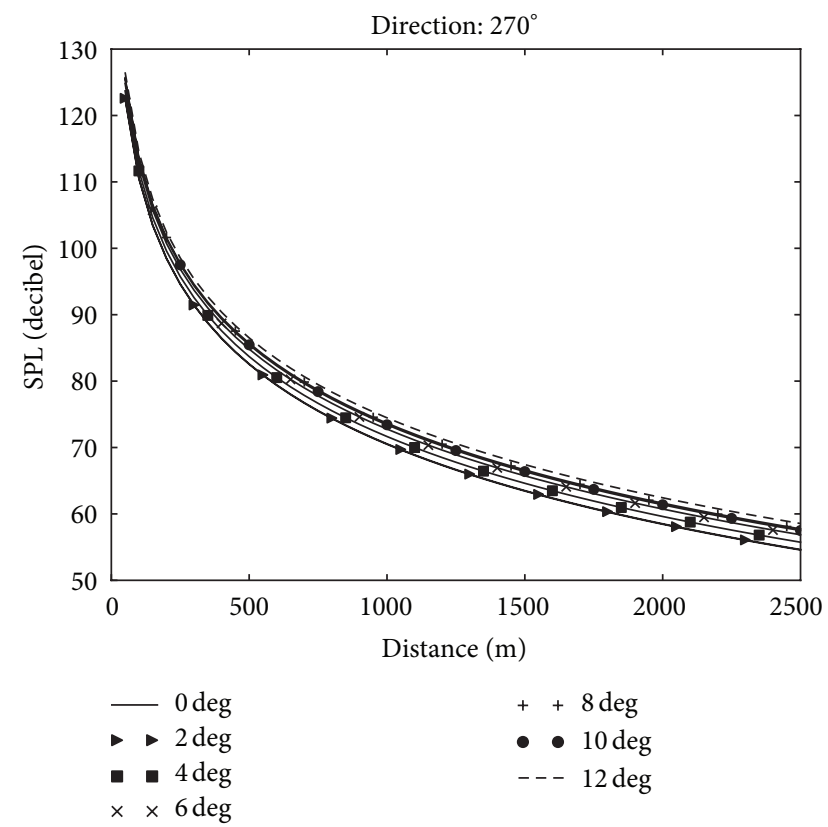

(d)

FIgURE 14: SPL (dB) of NACA0012 versus distance (m).

as in Figure 13, the comparison of the hydrofoils will be possible.

It is obviously clear from Figure 13, that from an acoustic perspective, the NACA0012 hydrofoil is a better choice for marine applications. As mentioned before, it is also important to know how the sound pressure level of the noise varies as the observer changes its distance from the source.

Here, by the use of the developed code ACOPY, the hydrofoil noise is calculated in 8 directions (as specified in Figure 5) and at distances ranging from $50 \mathrm{~m}$ to $2500 \mathrm{~m}$ from the hydrofoils. By plotting the results, it is observed that the SPL decreases as expected for all directions and for all angles of attack. The SPL data for each direction is plotted versus distance for the hydrofoil NACA0012 in Figure 14 and for hydrofoil NACA0018 in Figure 15. The isolines in each plot are related to different angles of attack as indicated by the legends.
The general trend and overall behavior of the SPL variation versus distance is the same for all directions. The operational noise region may also be extracted from these charts. In doing so, the behavior of both sections in each direction can be compared and analyzed. The operational noise regions for both sections are plotted in different directions in Figure 16.

It can be deduced from Figure 16 that the noise generated from NACA0012, as expected, is less than NACA0018 hydrofoil in all directions and at all distances.

\section{Conclusion}

In the design process of lifting surfaces for marine applications, acoustic noise emitted by the intended surface is one of the important parameters to be considered. The NACA foil 


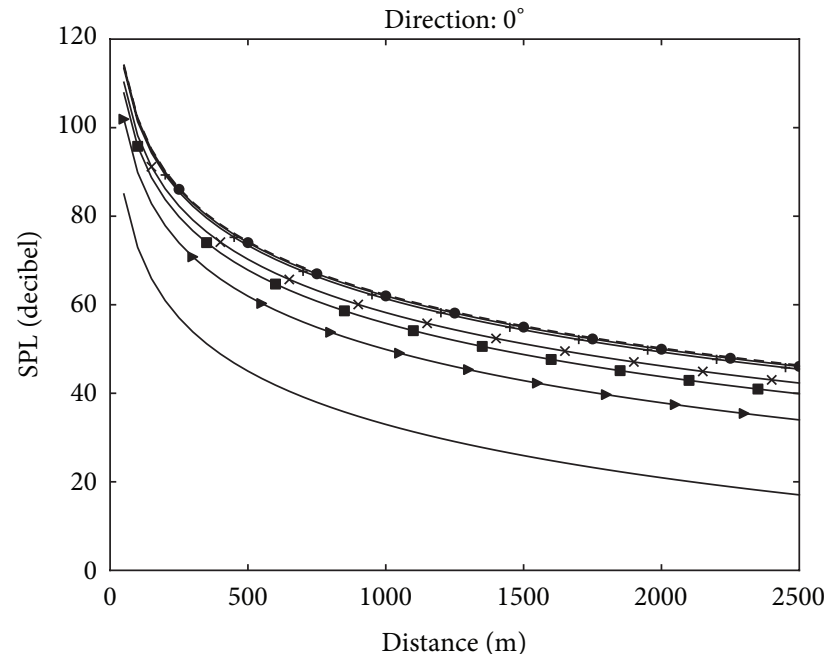

(a)

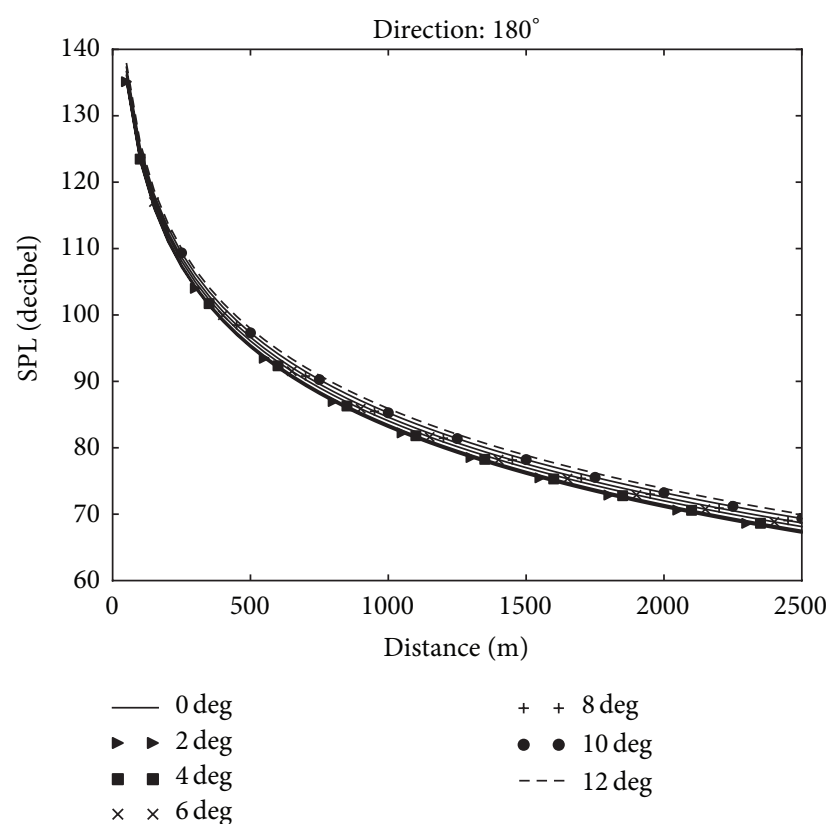

(c)

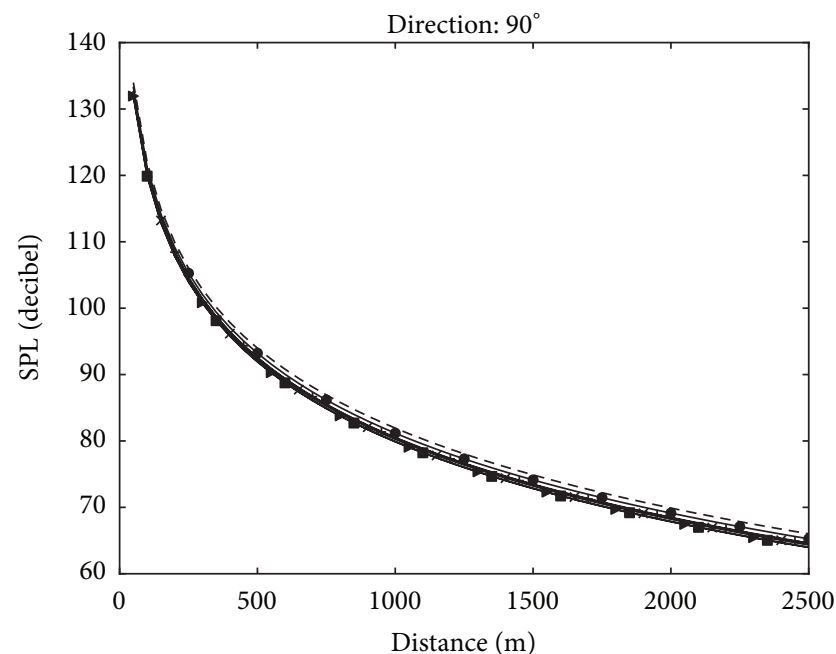

(b)

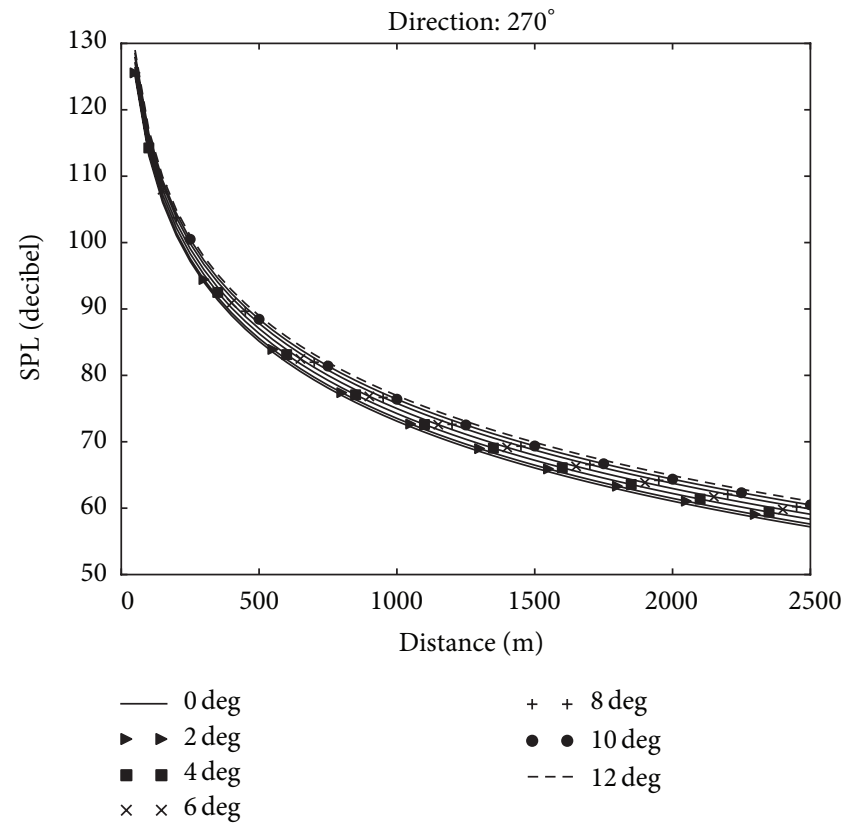

(d)

FigURE 15: SPL (dB) of NACA0018 versus distance (m).

series are the commonly used sections in marine applications. Accordingly, in the present work, hydroacoustic fields of NACA0012 and NACA0018 have been calculated and the acoustic behavior of these sections have been analyzed and compared at different angles of attack.

The Ansys-CFX Navier-stokes solver has been used to obtain the hydrodynamic pressure and velocity fields of the hydrofoils. The FW-H method has been explained and implemented for the acoustic analysis. Using the powerful multithreading ability of the Python programming language, an acoustic solver named ACOPY has been programmed and introduced. Both hydrodynamic and acoustic results have been validated with high accuracy.
A comparison between several integration surfaces has been conducted, and the best integration surface for implementing the FW-H method on hydrofoils has been introduced.

A complete investigation has been carried out on the behavior of the acoustic fields of the two mentioned hydrofoil sections. To compare the acoustic fields of these foil sections, the concept of operational noise regions has been defined, and by using this definition, the acoustic fields of the two sections have been compared, based on the operation of lifting surfaces in marine environments. The obtained results suggest that NACA0012 hydrofoil is a better choice, when the acoustic characteristics of the lifting surface are of concern. 


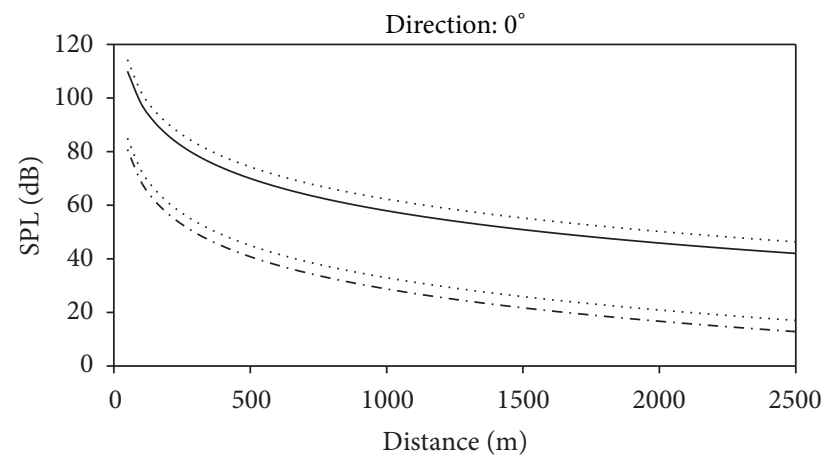

(a)

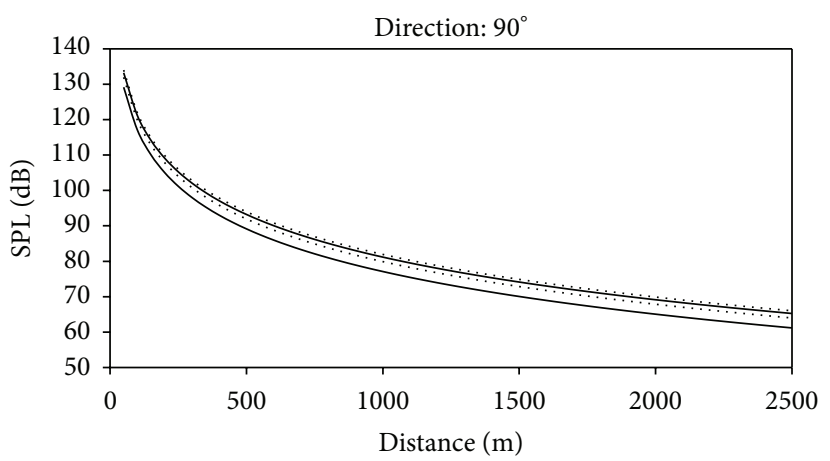

(c)

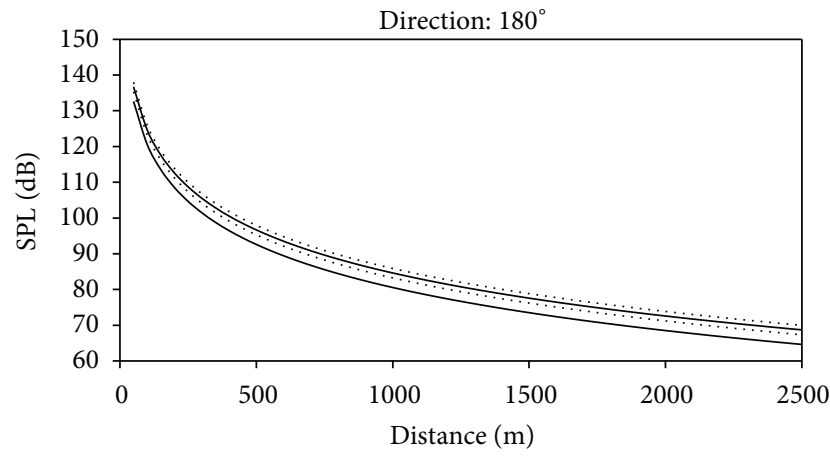

(e)

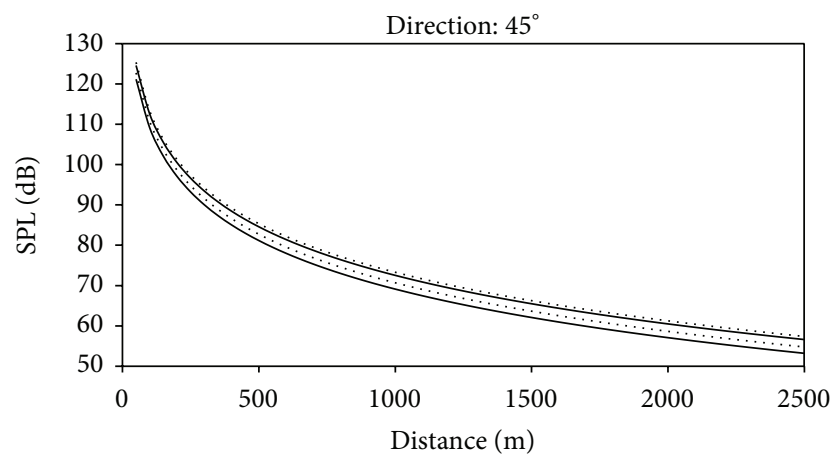

(b)

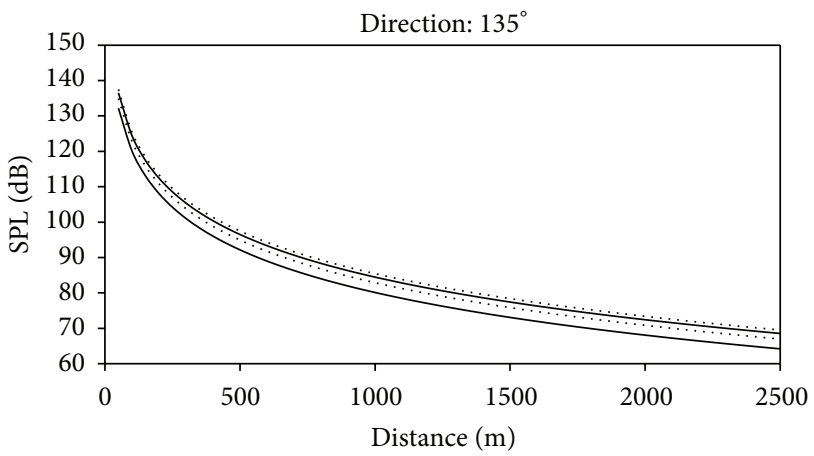

(d)

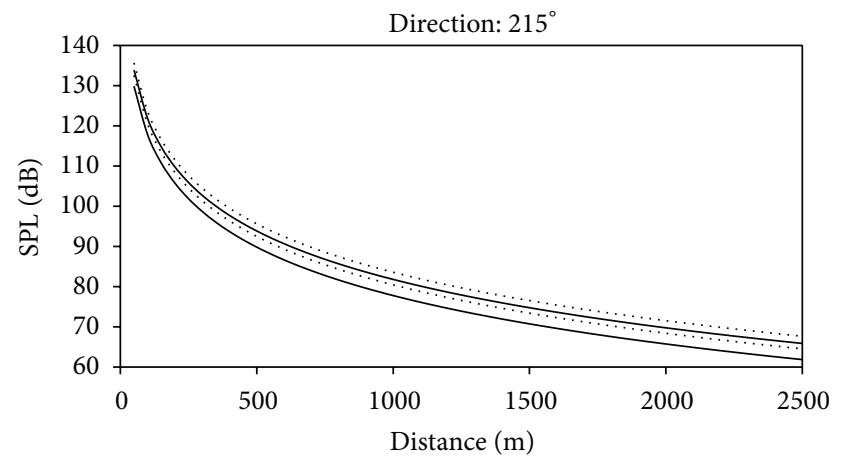

(f)

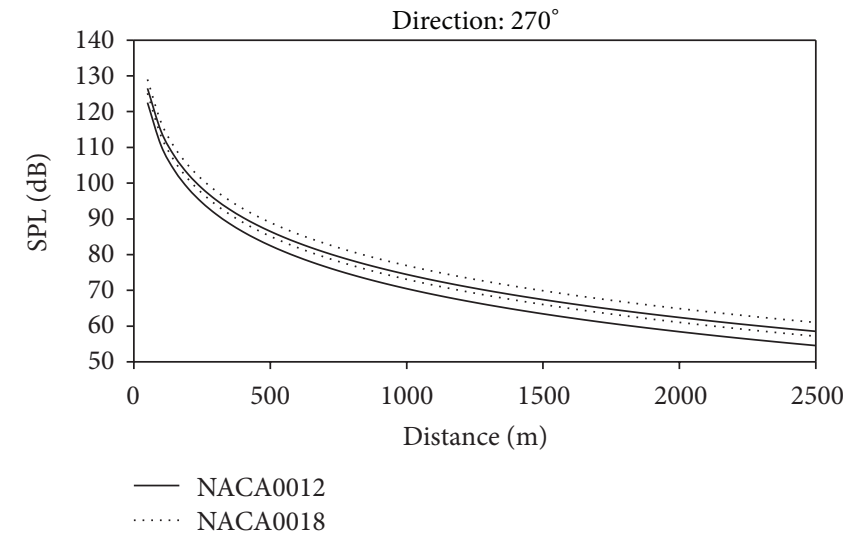

(g)

FIGURE 16: Comparative operational noise regions in different directions. 


\section{Conflict of Interests}

The authors of the paper, do not have a direct financial relation with any commercial identity mentioned in the paper that might lead to a conflict of interests.

\section{References}

[1] C. K. W. Tam and J. C. Webb, "Dispersion-relation-preserving finite difference schemes for computational acoustics," Journal of Computational Physics, vol. 107, no. 2, pp. 262-281, 1993.

[2] H. Shen and C. K. W. Tam, "Numerical simulation of the generation of axisymmetric mode jet screech tones," AIAA Journal, vol. 36, no. 10, pp. 1801-1807, 1998.

[3] S. A. Slimon, M. C. Soteriou, and D. W. Davis, "Development of computational aeroacoustics equations for subsonic flows using a Mach number expansion approach," Journal of Computational Physics, vol. 159, no. 2, pp. 377-406, 2000.

[4] J. C. Hardin and D. S. Pope, "An acoustic/viscous splitting technique for computational aeroacoustics," Theoretical and Computational Fluid Dynamics, vol. 6, no. 5-6, pp. 323-340, 1994.

[5] J. A. Ekaterinaris, "New formulation of Hardin-Pope equations for aeroacoustics," AIAA journal, vol. 37, no. 9, pp. 1033-1039, 1999.

[6] J. A. Ekaterinaris, "New formulation of Hardin-Pope equations for aeroacoustics," AIAA journal, vol. 37, no. 9, pp. 1033-1039, 1999.

[7] W. Z. Shen, J. A. Michelsen, and J. N. Sørensen, "A collocated grid finite volume method for aeroacoustic computations of low-speed flows," Journal of Computational Physics, vol. 196, no. 1, pp. 348-366, 2004.

[8] O. Marsden, C. Bogey, and C. Bailly, "Direct noise computation of the turbulent flow around a zero-incidence airfoil," AIAA Journal, vol. 46, no. 4, pp. 874-883, 2008.

[9] R. D. Sandberg, L. E. Jones, N. D. Sandham, and P. F. Joseph, "Direct numerical simulations of tonal noise generated by laminar flow past airfoils," Journal of Sound and Vibration, vol. 320, no. 4-5, pp. 838-858, 2009.

[10] M. J. Lighthill, "On sound generated aerodynamically. I: general theory," Proceedings of the Royal Society A, vol. 221, no. 1107, pp. 564-587, 1952.

[11] W. J. F. Willams and D. L. Hawkings, "Sound generation by turbulence and surfaces in arbitrary motion," Philosophical Transactions of the Royal Society of London A, vol. 264, no. 1151, pp. 321-342, 1969.

[12] F. Farassat and G. P. Succi, "The prediction of helicopter rotor discrete frequency noise," Vertica, vol. 7, no. 4, pp. 309-320, 1983.

[13] K. S. Brenter, Prediction of Helicopter Discrete Frequency Rotor Noise-A Computer Program Incorporating Realistic Blade Motions and Advanced formulation, NASA Langley Research Center, 1986.

[14] F. Farassat, Introduction to Generalized Functions with Applications in Aerodynamics and Aeroacoustics, vol. 3428, NASA Technical paper, 1996.

[15] K. S. Brentner, "An efficient and robust method for predicting helicopter high-speed impulsive noise," Journal of Sound and Vibration, vol. 203, no. 1, pp. 87-100, 1997.

[16] K. S. Brentner and F. Farassat, "Analytical comparison of the acoustic analogy and Kirchhoff formulation for moving surfaces," AIAA Journal, vol. 36, no. 8, pp. 1379-1386, 1998.
[17] F. Farassat and K. S. Brentner, "The uses and abuses of the acoustic analogy in helicopter rotor noise prediction," Journal of the American Helicopter Society, vol. 33, no. 1, pp. 29-36, 1988.

[18] J. B. Freund, "A simple method for computing far-field sound in aeroacoustic computations," Journal of Computational Physics, vol. 157, no. 2, pp. 796-800, 2000.

[19] B. A. Singer, K. S. Brentner, D. P. Lockard, and G. M. Lilley, "Simulation of acoustic scattering from a trailing edge," Journal of Sound and Vibration, vol. 230, no. 3, pp. 541-560, 2000.

[20] A. S. Lyrintzis, "Integral methods in computational aeroacoustics from the (Cfd) near-field to the (acoustic) far-field," in CEAS Workshop, Athens Greece, November 2002.

[21] J. Casper and F. Farassat, "Broadband trailing edge noise predictions in the time domain," Journal of Sound and Vibration, vol. 271, no. 1-2, pp. 159-176, 2004.

[22] W. J. Zhu, Aero-Acoustic Computations of Wind Turbines, Department of Mechanical Engineering, Technical University of Denmark, 2007.

[23] F. Farassat and M. K. Myers, "Extension of Kirchhoff's formula to radiation from moving surfaces," Journal of Sound and Vibration, vol. 123, no. 3, pp. 451-460, 1988.

[24] H. M. Atassi and S. Subramaniam, "Acoustic radiation from lifting airfoils in compressible subsonic flow," in 13th Aeroacoustics Conference, pp. 22-24, October 1990.

[25] R. E. Sheldahl and P. C. Klimas, "Aerodynamic characteristics of seven airfoil sections through 180 degrees angle of attack for use in aerodynamic analysis of vertical axis wind turbines," Tech. Rep. SAND80-2114, Sandia National Laboratories, Albuquerque, Mexico, 1981. 

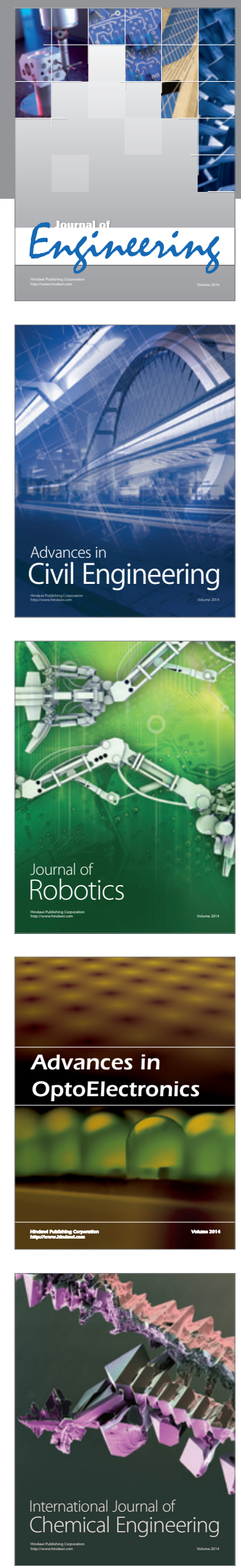

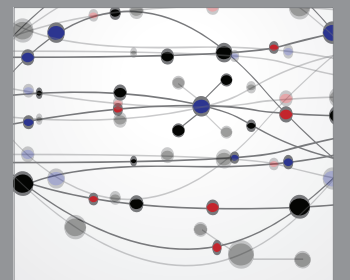

The Scientific World Journal
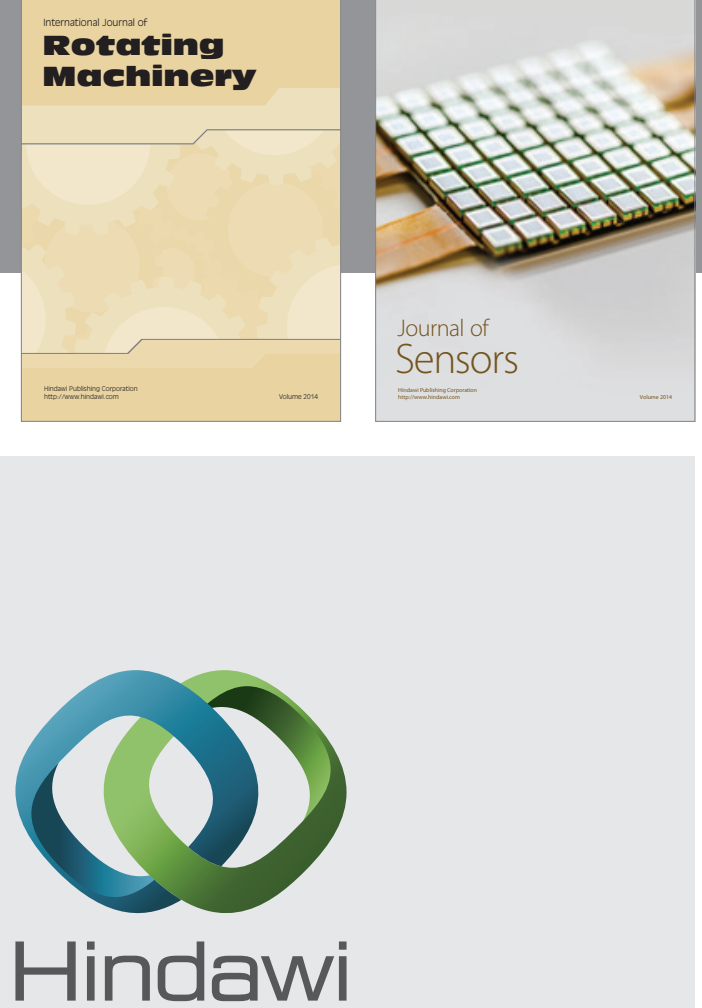

Submit your manuscripts at http://www.hindawi.com
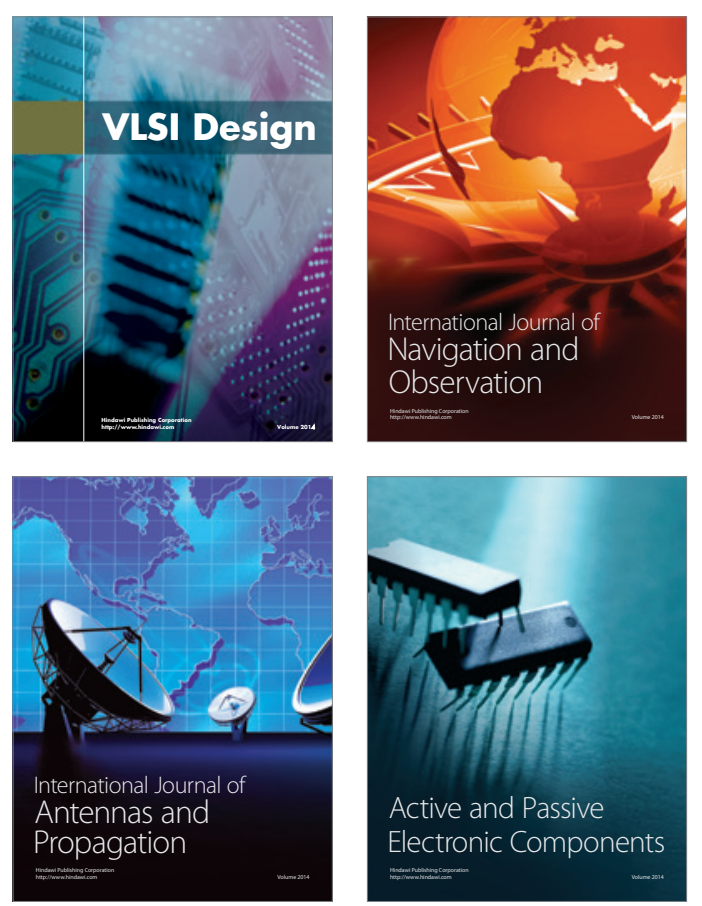
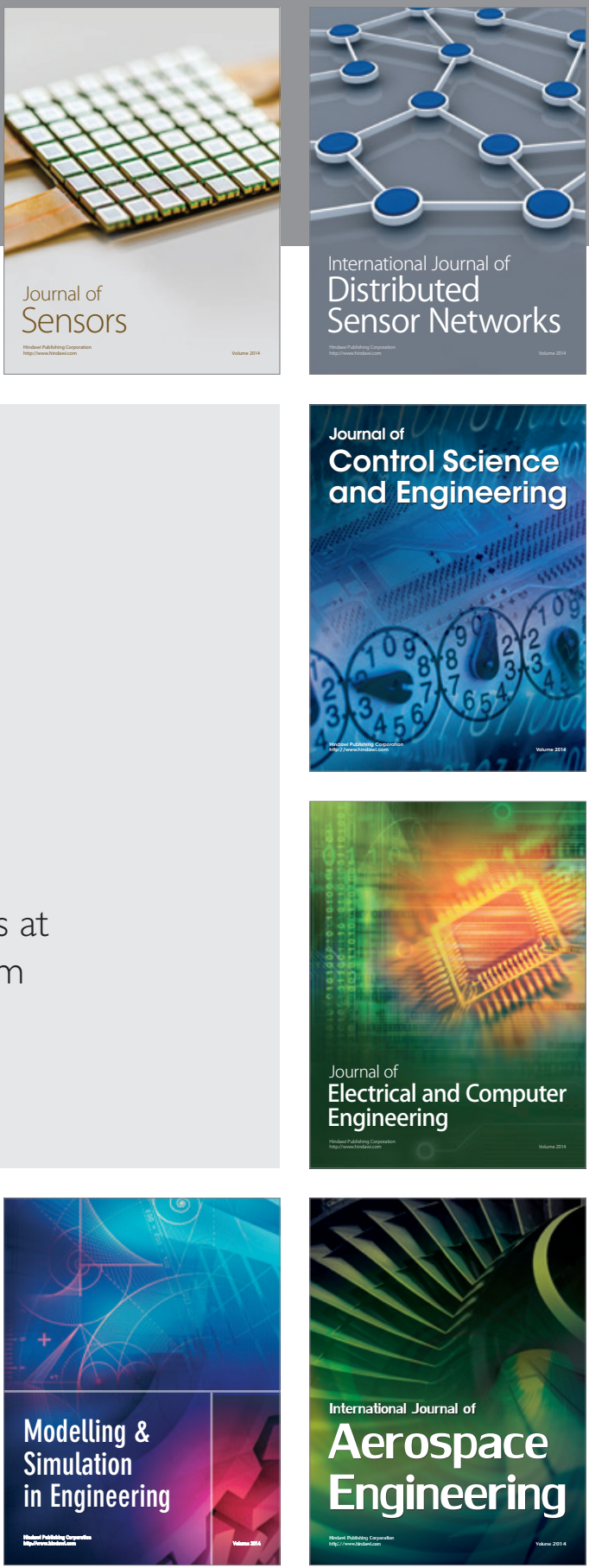

Journal of

Control Science

and Engineering
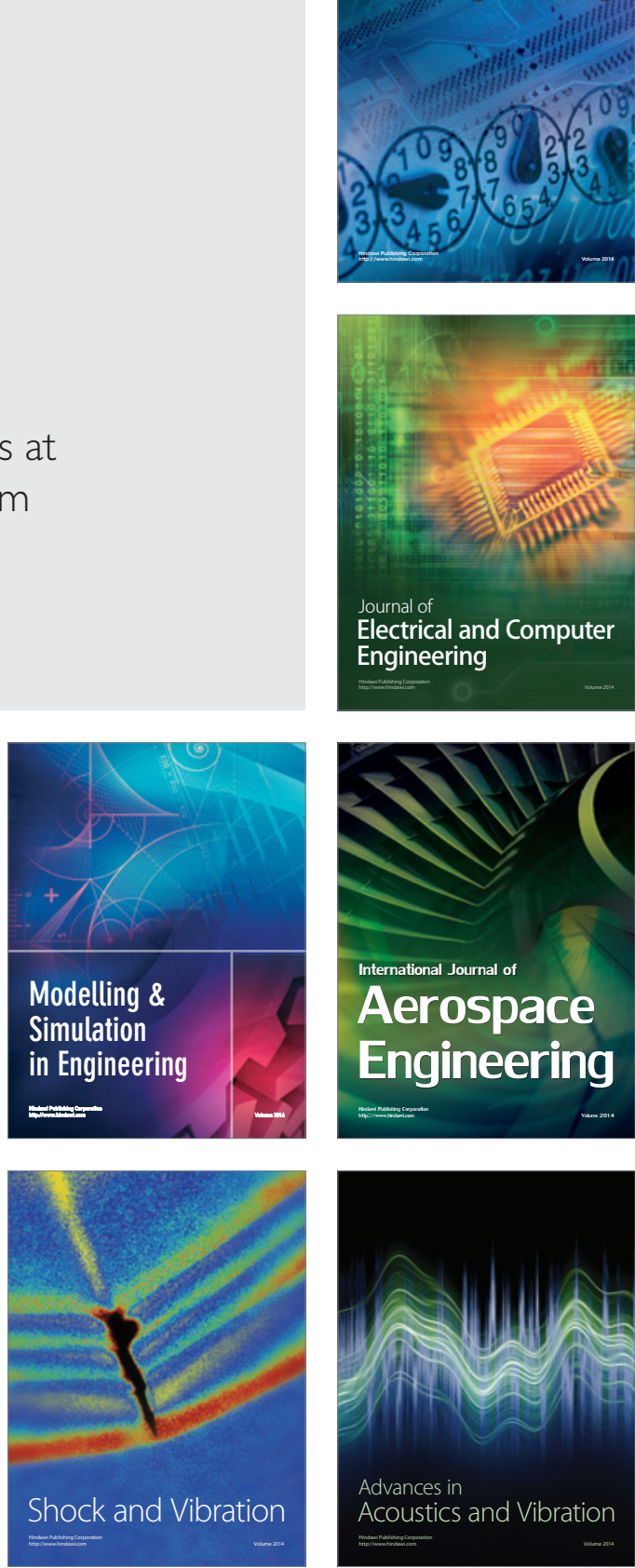